\title{
Philosophy, Adversarial Argumentation, and Embattled Reason
}

\author{
Phyllis RoOney
}

Department of Philosophy

Oakland University

Rochester, Michigan 48309, USA

Email: rooney@oakland.edu

\begin{abstract}
Philosophy's adversarial argumentation style is often noted as a factor contributing to the low numbers of women in philosophy. I argue that there is a level of adversariality peculiar to philosophy that merits specific feminist examination, yet doesn't assume controversial gender differences claims. The dominance of the argument-as-war metaphor is not warranted, since this metaphor misconstrues the epistemic role of good argument as a tool of rational persuasion. This metaphor is entangled with the persisting narrative of embattled reason, which, in turn, is linked to the sexism-informed narrative of the "man of reason" continually warding off or battling "feminine" unreason.
\end{abstract}

Resumé: On note souvent que le style combatif de l'argumentation en philosophie est un facteur qui contribue au nombre faible de femmes en philosophie. J'avance qu'il y a un niveau d'antagonisme propre à la philosophie qui mérite un examen spécifiquement féministe, mais qui ne suppose pas des jugements controversés sur les différents rôles attendus des hommes et des femmes. La prédominance de la métaphore de l'argument-comme-laguerre n'est pas justifiée, car elle interprète mal le rôle épistémique qu'un bon argument joue comme outil de persuasion rationnelle. Cette métaphore est embrouillée avec la tradition persistante de la raison combative, qui se lie à la tradition sexiste de «l'homme de la raison» qui détourne ou combat toujours la déraison «féminine».

Keywords: adversarial argumentation, adversary paradigm, argument-as-war, embattled reason, equity in philosophy, feminism, gender differences, man of reason

\section{Philosophy's woman problem}

Philosophy's woman problem has recently garnered attention outside philosophy circles, though it has been a concern for women in philosophy for some time. This past October (2009) an article in the New York Times, "A Dearth of Woman Philosophers," noted that in the United States and Britain, women make up about $20 \%$ of academic philosophers. ${ }^{1}$ This is noteworthy since, after decades of

${ }^{1}$ New York Times, October 2, 2009. Available at:

(C) Phyllis Rooney. Informal Logic, Vol. 30, No. 3 (2010), pp. 203-234. 
affirmative intention (if not action) designed to counter centuries of academic exclusion and discouragement, women now comprise close to $40 \%$ of academic staff in most other disciplines in the humanities and social sciences. ${ }^{2}$ The Times piece made significant reference to an article by Brooke Lewis published some weeks earlier in The Philosopher's Magazine (TPM) which raised the question of whether philosophy's reputation as a "white men's club" is deserved, and what might account for the persistence of the gender imbalance, in particular (Lewis, 2009). Helen Beebee, Director of the British Philosophical Association, is quoted in both articles as suggesting that part of the reason for the lower numbers of women in philosophy is that women are turned off by a culture of aggressive argument particular to the discipline. Beebee remarks, "I can remember being a $\mathrm{PhD}$ student and giving seminar papers and just being absolutely terrified that I was going to wind up intellectually beaten to a pulp by the audience. I can easily imagine someone thinking, 'this is just ridiculous, why should I want to pursue a career where I open myself up to having my work publicly trashed on a regular basis?"”

Beebe is not the first to link philosophy's gender imbalance with a male-inflected aggressive and adversarial style of argumentation regularly practiced in the discipline. Drawing from our experiences and observations, many women philosophers make similar connections. In addition, in the comparatively few philosophy contexts dominated by women (feminist philosophy seminars and conferences, for instance), one notices a concerted effort among participants to counter the adversarial and agonistic style of maledominated philosophy discussions with more measured, constructive criticism of philosophy theses and papers. There has been a growing awareness that such reflexive attention to style and method of argumentation not only helps to address the gender imbalance in philosophy, but it sustains better philosophical discus-

http://ideas.blogs.nytimes.com/2009/10/02/a-dearth-of-women-philosophers/

See the Spring 2009 (vol. 8, no. 2) and Fall 2009 (vol. 9, no.1) issues of the American Philosophical Association Newsletter on Feminism and Philosophy for important discussions about the numbers of women in Philosophy (US, 21\%), and about ways to address equity concerns. These newsletters are available at the American Philosophical Association's website, at: http://www.apaonline.org/publications/newsletters/index.aspx.

In what is a likely result of recommendations adopted by the Canadian Philosophical Association (CPA) in the early 1990s, the percentage of women in fulltime tenured or tenure-tract philosophy positions in Canada is notably betterfigures from 2008-09 indicate that it is close to 30\%. For discussion and analysis of the data, see the CPA website:

http://www.acpcpa.ca/documents/Survey \%202009\%20Final\%20Report $\% 20$ En.p df.

${ }^{2}$ According to a U. S. Department of Education report from 2004, women make up $41 \%$ of faculty in most other humanities disciplines. For a discussion of this and other relevant data see Crasnow 2009. 
sion and, in turn, better philosophy. Philosopher Jennifer Saul remarks (in the TPM article), "I think that the very combative 'out to destroy the speaker' sort of philosophy is something that a lot of women find uncomfortable. But I wouldn't want to say it's just a problem for women-I think it's a problem for men and a problem for philosophy because I don't think it's a good way to do philosophy" (Lewis, 2009).

Saul's comment echoes the two main concerns raised by Janice Moulton in her classic paper on women, argumentation, and philosophy. The "Adversary Paradigm," Moulton maintains, values aggression in a way that discourages more women than men from philosophy. In addition, it is not good for philosophy since it constrains philosophical argumentation: "when [the Adversary Method in its role as a paradigm] dominates the methodology and evaluation of philosophy, it restricts and misrepresents what philosophic reasoning is" (Moulton, 1983, p. 153). Among other things, Moulton argues, the Adversary Paradigm misrepresents the history of philosophy ("philosophers who cannot be recast into the adversarial mold are likely to be ignored"); it puts more emphasis on winning points than on convincing (or it conflates these two goals); it grants greater recognition to problems that are articulated in terms of opposing positions; and it "[gives] undue attention and publicity to positions merely because they are those of a hypothetical adversary and possibly ignoring positions which make more valuable or interesting claims" ( Moulton, 1983, p. 158). I agree with Moulton that, for these and other reasons, the Adversary Paradigm either "leads to bad reasoning" in philosophy or, at the very least, it sustains a more limited range of reasoning and argument forms and practices than good philosophical insight and development surely merit.

Moulton's paper, however, like the comment by Saul, presents the two concerns with adversarial argumentation in philosophy as somewhat separate concerns. Moulton's arguments addressing the second concern (the limited philosophical method concern) proceed largely independently of the concern that women may be less comfortable with adversarial argumentation, that is, many of her arguments stand even if women and men were equally comfortable with a combative style. More particularly, while the gender concern seems clearly a feminist one, Moulton's arguments about limited philosophical method are not based on specifically-feminist examinations. (This is less a critique of her arguments than it is a description of the theoretical resources she brings to bear on them.) She connects the two concerns by linking the persistence of the Adversary Paradigm in philosophy (despite its limitations) to the general cultural association of aggression with masculinity and, in turn, with competence and success. She notes that, while aggression is often considered a negative trait, "when it is specifically 
connected to males qua males... [it] often takes on positive associations...[in professions such as politics, sales, law, and philosophy] aggression is thought to be related to positive concepts such as power, activity, ambition, authority, competence, and effectiveness - concepts that are related to success in these professions" ( $p$. 149).

Feminist activism and theorizing during these past decades have helped to dislodge some aspects of the general cultural association of aggression and masculinity with competence and success. In educational settings, for example, women have been encouraged to assert themselves and to challenge traditional stereotypes linking femininity with passivity and submissiveness. Women have made notable advances in many academic disciplines that require proficiency in presenting, challenging, and defending arguments, whether in written theses, dissertations, and journal articles, or in oral debate in seminars, conferences, and job talks. ${ }^{3}$ In addition, women now comprise close to $50 \%$ of law school admissions in many places, doing well in a discipline and profession based on adversarial forms of argumentation. Thus, despite some gains, philosophy stands out as something of an anomaly. The lingering gender imbalance there, along with recurring mention of adversarial argumentation as a contributing factor, raises questions about whether philosophy still sustains a type of male-inflected adversariality peculiar to the discipline. I will argue that it does, and that this adversariality requires specifically-feminist philosophical examination. While I do not disagree with many of Moulton's arguments about the limitations of the Adversary Paradigm in philosophy, I think they merit further development and expansion, drawing specifically on feminist philosophical work developed since the 1983 publication of her important paper. Though feminist work in moral, social, and political philosophy was already underway by then, Moulton's paper originally appeared in a groundbreaking volume in the development of feminist perspectives in epistemology, metaphysics, methodology, and philosophy of science, Discovering Reality (Harding and Hintikka, 1983).

A third notable (extra-philosophy) article addressing philosophy's woman problem - one that also appeared last Octoberdraws particular attention to the significance of feminist philosophy. In an article in The Chronicle of Higher Education, Regan Pe-

\footnotetext{
${ }^{3}$ For example, Olivia Frey (1990) examined the papers published in PMLA (the journal of the Modern Language Association of America) from 1977 to 1985 and concluded that all but two used "some version of the adversarial method" (p. 512), often beginning with an attack on the views of earlier authors. The two exceptions are by "critics who have thought about how they are going to disagree, and have done it, respectfully, without sarcasm or innuendo or statements suggesting 'wrong-headedness,' 'reluctance,' 'confusion,' or 'stupidity'” (p. $521)$.
} 
naluna reflects on the low numbers of women earning bachelor's degrees in philosophy. She notes that US Department of Education statistics from 2006-07 reveal that women earned 31\% of philosophy degrees, compared to $41 \%$ of history degrees, $45 \%$ in mathematics, $60 \%$ in biology, and 69\% in English. ${ }^{4}$ Penaluna argues that we cannot overlook sexism and misogyny in the Western philosophical canon in explaining women's disaffection with the discipline. Drawing attention to this same concern, Janet Kourany succinctly describes the problem that has significantly motivated and defined the project of feminist philosophy:

Feminist research into the history of philosophy... discloses that many of the greatest philosophers have held deeply misogynist views of women, views that shaped some of the most important parts of their philosophies. Thus, women have been characterized as rationally deficient (Aristotle), incapable of emotional self-control (Plato) or principled behavior (Kant), and more susceptible to sin (Aquinas), whose only function is to bear robust children (Nietzsche). And the concepts of justice (Plato) and moral worth (Kant) and the good life (Aristotle) have been modeled not on them but on what is held to be their opposite-men. There is much in the philosophic canon, therefore, that might alienate wouldbe women philosophers. (Kourany, 2009, p. 9)

Philosophy, in effect, has had a woman problem for well over two millennia! Noting similar "canonical" views about women in connection with women's entry into the discipline, Penaluna interjects, "How is that for a welcome mat?"

Penaluna remarks that other disciplines such as English and history also have male-dominated canons, and one explanation for why there are more women in these areas is that "researchers and teachers in those fields have taken steps to offset the negative consequences of a male-dominated canon...[but] philosophers are reluctant to take on a feminist critique of the canon" (Penaluna, 2009). Her observation is borne out by that fact that, though it has been significantly invested (for over a quarter century now) in uncovering and counteracting the various effects of sexist and misogynist theorizing, feminist philosophy is still significantly mar-

\footnotetext{
4 Penaluna 2009. This United States percentage of women earning bachelor degrees in philosophy contrasts interestingly with Beebee's "impression" that in the United Kingdom "there are roughly equal numbers of men and women graduating with good bachelor degrees in philosophy." There the numbers of women drop off at the MA level, and then again at the PhD level (Lewis, 2009). The comparison with mathematics (45\%) is noteworthy, given that mathematics has also been traditionally viewed as a "male" discipline of reasoning.
} 
ginalized in the discipline. Some have identified elements of "backlash" in this marginalization. ${ }^{5}$ Others have also stressed a link between the low numbers of women in philosophy and the discipline's particular resistance to feminist philosophy. Sally Haslanger notes this link in her paper examining how the "ideology and culture of philosophy" still sustains subtle or not-so-subtle forms of discrimination against women. Not only does an examination of the papers published in seven top philosophy journals from 2002 to 2007 suggest that there is gender bias in the evaluation process, but, Haslanger adds, "The virtual absence of feminist philosophy in the journals considered stands in stark contrast to the acceptance of feminist work in other humanities and social sciences. Philosophy is, and is generally perceived to be, reactionary in this respect" (Haslanger, 2008, p. 216).

The marginalization of feminist work suggests that philosophy's current woman problem is, in no small part, a lingering effect of its long historical woman problem. Its historical problem significantly contributed to the epistemic subordination and disenfranchisement of women, both in the general culture and in the discipline itself. More particularly, philosophical theorizing about the natures of women, men, reason, and knowledge reinforced the cultural dismissal and denigration of women as reasoners, knowers, or credible authorities; it thus contributed to their exclusion from educational, academic, and other public institutions of social and political influence which were thereby normalized as male places. Quite specifically, women's supposed deficiencies in reasoning excluded them from philosophy which was understood as a (if not the) discipline of reason. This supposition, I suspect, is still playing a role in the marginalization or denigration of feminist philosophy. As the first significant area in philosophy developed primarily by women, it is not accorded the same careful reading, reasoning, and integration that is normally accorded projects in philosophy developed primarily by men. Yet feminist philosophy aims to uncover and elucidate this and other effects of philosophy's sexist historyincluding its effects in philosophical theorizing about justice, morality, reason, and argument, concepts that initially seem to have little to do with gender. So we have a conundrum. Philosophy resists the very thing (feminist philosophy) that helps to uncover and mitigate the lingering effects of the historical roots of that same resistance, producing a kind of vicious circle that, to my mind, is especially problematic in philosophy, and contributes to the peculiarity of its gender imbalance.

\footnotetext{
${ }^{5}$ See Burgess-Jackson (2002). Many of the other papers in Superson and Cudd (2002) also address the backlash against feminist philosophy. I examine the marginalization of feminist epistemology, in particular, in Rooney (forthcoming).
} 
My goal is to advance an understanding of feminist concerns with adversarial argumentation as concerns that are bound up, entangled with philosophy's sexist history, and with the ways in which that history informed theorizing about reason and argument. Toward that end, I will argue (in section 2 below) that we first need to disentangle adversariality, specifically as a feminist philosophical concern, from the issue about gender differences in styles or types of argumentation. I do not deny that such differences may still pertain in many contexts (including philosophical ones), that they still reflect problematic gender socialization and stereotyping, as well as cultural determinations of competence and authority, and that, if so, they merit significant feminist attention. The feminist philosophical concern with adversarial argumentation, as I develop it here, is directed primarily to the tradition and culture of philosophy, and, in particular, to philosophical conceptions and understandings of reason and of argument understood as a paradigm example of reasoning. However, I think that a full feminist accounting of the general cultural problem with gender, adversariality, and authority must include consideration of philosophy's history and its lingering effects. As we will see, such an inclusion counsels care in the way we articulate and examine gender differences, lest we reinforce historical associations that, instead, need feminist uprooting.

The terms "Adversary Paradigm" and "adversarial argumentation" can mean various things, and we need to be mindful of this when we elucidate feminist concerns with adversariality. On the one hand, the terms are associated with hostility and combativeness in argumentation, with an aggressive atmosphere that can include name-calling, put-downs, or quips such as "that's a ridiculous argument!" On the other hand, the terms can be associated with nonaggressive, respectful disagreement and debate between "adversaries" who hold different or opposite positions on some matter. In reality, including in philosophy, argumentation regularly falls somewhere in between, sometimes leaning more toward the aggressive end, sometimes more toward the respectful disagreement end. Although philosophical argumentation ideally purports to be about respectful disagreement and debate, Moulton argues that the dominance of the Adversary Method not only constrains the methodology of philosophy into an oppositional reasoning model, but it also creates "conditions of hostility [that] are not likely to elicit the best reasoning." "Yet even though she argues for connections among different problematic aspects of the Adversary Paradigm, Moulton sometimes runs them together when more distinctions are

\footnotetext{
${ }^{6}$ Moulton, 1983, p. 153. By "oppositional reasoning" I mean reasoning and arguing that is largely structured in terms of opponents and opposing positions, attacks and defenses, winners and losers.
} 


\section{0}

Phyllis Rooney

needed. ${ }^{7}$ The hostility issue is different from the concern with the dominance of oppositional reasoning in philosophy: "opponents" in argument can proceed in a respectful manner without elements of aggression or hostility - they often do. Specifically-feminist concerns with either issue might also be different, even if, as I will argue below, the concerns are linked.

Trudy Govier's distinction between ancillary adversariality and minimal adversariality captures the difference between hostile and respectful forms of argumentation, and it also helps to clarify some of the feminist concerns with adversarial argumentation. Many feminist criticisms, Govier notes, are directed toward "ancillary adversariality," the hostility, name-calling, rudeness, intolerance, and quarrelsomeness that can infuse argument situations (Govier, 1999, p. 245). In philosophy, in particular, we might include ancillary adversariality among the factors that contribute to what Haslanger calls the "hypermasculine places" philosophy departments often are. ${ }^{8}$ Govier does not disagree with feminists who critique argumentative practices that reflect socially-encouraged masculine forms of ancillary aggression and combativeness that discourage many women. Yet these forms of ancillary adversariality should be discouraged in any case, she argues, because they are not consistent with good argument practice that involves respectful exchange of evidence and ideas. However, Govier adds, such respectful exchange typically involves differences and disagreements in beliefs and positions and, as such, it involves "minimal adversariality," a basic level of adversariality that need not be negative in the way that ancillary adversariality is.

I will argue in section 3 that while Govier's distinction is helpful in clarifying different feminist concerns with adversariality, it does not quite address the feminist issue as I develop it in this paper. Though she is certainly concerned with combative climate factors that may disproportionately discourage women, Govier's argument against ancillary adversariality does not draw on feminist work on reason, argument, and the history of philosophy. As such, her argument is not unlike Moulton's (limited philosophical method) argument against the Adversary Paradigm. As is the case with Moulton's argument, I do not disagree with Govier's argu-

\footnotetext{
${ }^{7}$ Jean Grimshaw argues that Moulton's terms and arguments sometimes shift in a problematic way, for example, "from a consideration of the relation between the participants in a debate or discussion, to a consideration of the relation between a person and some view or theory" (Grimshaw, 1987, p. 19).

8 In sustaining a competitive, combative, hostile to femininity, and highly judgmental climate, Haslanger notes, philosophy departments are often "socially dysfunctional places" where women, who are often socialized to feel responsible for maintaining good social dynamics, may feel either burdened or "alienated by an atmosphere where ordinary social norms are not recognized" (Haslanger, 2008, p. 217).
} 
ment as much as I want to push it further along feminist lines. For a start, we might ask why many male philosophers so readily conform to modes of aggressive or ancillary adversariality that, as both Moulton and Govier make evident, conflict with standard philosophical norms of good reasoning and argumentation. My examination will also address Govier's argument for the acceptability of minimal adversariality. I agree with her that argumentation is typically based in differences and disagreements about claims or positions, and I would stress that such disagreement is often a significant driving force in constructive philosophical development, including feminist philosophical development. Yet, even granting the positive role of disagreement, I question her claim that minimal adversariality is just about inevitable in the working out of disagreement. More specifically, I will contend that the distinction between minimal and ancillary adversariality is not as clear as Govier thinks: the slide from either one to the other is more slippery than we might suppose or, indeed, hope. I will argue that we need to carefully examine the move from difference and disagreement to opposition and adversariality, not simply because the latter may be uncomfortable for some discussants, but because the move to the latter misconstrues the epistemic role of good argument as a significant tool of rational persuasion in the acquisition and communication of truths or likely truths.

As Govier and others admit, the move from disagreement to adversariality is rendered easy, perhaps inevitable, by the embeddedness of the argument-as-war metaphor in both the conceptualization and practice of argument. ${ }^{9}$ When we talk about opponents, about adopting and defending positions, scoring points, or, simply, winning and losing arguments, it is difficult to know how we might articulate the things we mean by these phrases without using these warring and related sports metaphors. Yet embedded as it is, we can and should attempt to pry loose this metaphor in our thinking about argument and in our practice of argument. Toward that end, as I will argue in section 4, a necessary first step involves acknowledging the entanglement of this metaphor with the long historical narrative of reason as embattled, as continually warding off and defending against the ever-lurking threats of unreason or irrationality. I will also contend that this metaphor of embattled reason is significantly compelled by the recurring historical metaphorical gendering of reason, by the persistent depiction of the "man of reason" as continually battling aspects of unreason regularly constructed as womanly or "feminine"-passion, instinct, na-

\footnotetext{
${ }^{9}$ Discussion of the "ARGUMENT IS WAR" metaphor features significantly in Lakoff and Johnson's Metaphors We Live By (1980). It serves as their first example of a "conceptual metaphor...we live by in this culture: it structures the actions we perform in arguing" (1980, p. 4).
} 


\section{Phyllis Rooney}

ture, body, unruly bodily intrusions, or distracting charms. To my mind, this is a key insight in feminist philosophy that warrants much greater attention in philosophy and in argumentation theory more generally. Without this insight and its further elaboration, philosophical understandings and theories of argument and argumentation are likely to remain more limited than they need to be. This limitation continues to significantly constrain practices of reasoning and argumentation, both inside and outside the discipline of philosophy.

\section{Disentangling differences}

There are two kinds of claims about gender differences that have featured in feminist debates about argumentation. One, already noted, is the claim about gender differences in comfort levels with adversariality in argumentation. It is a claim about styles of arguing, sometimes spelled out as the claim that, in large part due to their socialization, women are more cooperative and supportive while men are more confrontational and combative in discussion and debate. Although my paper addresses the feminist issue with adversariality as somewhat separable from the different comfort levels concern, I am not suggesting that the latter is insignificant in philosophy. Anecdotal evidence certainly indicates that it is a factor in the discipline's continuing gender imbalance. However, given that some women are quite comfortable with adversarial argumentation (whether minimal or ancillary) and some men less so, the more general question we need to address in philosophy is whether facility with adversarial argumentation (particularly in oral discussion, though it can play out too in written work) plays a greater role in professional encouragement and advancement than is warranted. I've heard many philosophy teachers comment on classes in which the best papers were written by students who never or rarely spoke up in class discussion. (Indeed, I've had a few classes where I wondered if there might be an inverse relationship between assertion in discussion and quality of written work!) Thus, while public presentation and defense of one's views is to be encouraged, it may not be the significant measure of philosophical interest and talent that its role in disciplinary advancement presumes. In addition, more taciturn students who are commended on their written work might still feel discouraged when they perceive the role that being "good on one's feet" plays in philosophy. Types or levels of adversarial argumentation might also be examined in connection with other culturally-inflected practices of speech, attention, and interaction that are encouraged or discouraged in philosophy, practices that may also account for significant race and class imbalances in the discipline. 
The second gender difference claim, though it is sometimes entangled with the first, is a claim about types of argument. Men, it has been claimed, lean more towards abstract and linear reasoning and arguments, and women more towards contextual and narrative arguments. This second difference claim has often been linked with assertions about women's "different" ways of thinking, reasoning, or knowing. For example, Deborah Orr (1989) connects her discussion of female and male "modes" of rationality and argument with Carol Gilligan's much-discussed work on gender and moral deliberation. ${ }^{10}$ While the male-inflected "ethic of justice" emphasizes deductive reasoning from abstract principles, Orr notes, the femaleinflected "ethic of care" favors a style or mode that is contextual and narrative. However, these difference claims have been quite contentious in feminist theorizing, not least because empirical investigations have not consistently yielded significant gender difference across different situations and contexts, and separable from other social variables such as race and class. In particular, Sandra Menssen argues that "the work of Carol Gilligan and her associates does not give us good reason for believing that men and women use different logics, and...it is difficult even to illustrate 'the feminine mode of rationality' Orr asks us to acknowledge" (Menssen, 1993, p. 136). While I cannot address all of the concerns with claims about gender differences here, I want to examine some that are especially pertinent to my discussion about feminism and the theory and practice of argument in philosophy. ${ }^{11}$

Suppositions about some different-but-equal "women's ways of arguing" succumb to many of the same critiques that suppositions about a women's "care voice" or "women's ways of knowing" did in feminist ethics and feminist epistemology. Although debates about the empirical and philosophical status of a proposed ethic of care have contributed to the development of feminist ethics, that area cannot be identified with an ethic of care-though many still make that mistaken identification. Further empirical studies (subsequent to Gilligan's) rendered the existence, extent, or generalizability of gender differences questionable. In addition, many feminist theorists argued that even if women in some contexts are more likely to speak in a different care voice, this was not

10 See Gilligan (1982). Gilligan's work proved to be a significant catalyst for feminist debates about gender and moral reasoning., and it influenced debates about gender and cognitive differences more generally.

${ }_{11}$ It should be noted that some feminist work on argumentation and critical thinking does not rely on disputed claims about gender differences. In her feminist examination of the Critical Thinking tradition, Karen Warren (1988) argues that it is "patriarchal conceptual frameworks" that need to be the focus of feminist attention. These conceptual frameworks, she argues, are oppressive in that they often incorporate "value-hierarchical thinking," and they support structures of argumentation that maintain the subordination of "inferior" groups. 


\section{Phyllis Rooney}

something that could be readily affirmed by feminists (as a different yet equally valuable voice), since it could well bespeak the voice of the oppressed, and feminist endorsement would then amount to a kind of normalization of that oppression. ${ }^{12}$ A similar argument can be made about women's "different" styles or types of argument. To the extent that women's cooperative style or contextual elaboration indicates a tendency to defer, or a hesitancy about adopting and defending a position, it may bespeak women's diminished sense of cognitive authority and, as such, merits feminist redress rather than endorsement. Studies finding gender differences in cognitive capacities and practices are also rendered less than transparent by the complex role that gender stereotypes and expectations play, on the part of subjects, data collectors, and theoretical interpreters and commentators. For example, M. Lane Bruner has examined studies on gender and argumentation (conducted by scholars in Rhetoric and Communication) and concludes that many of them "tend to reify gender stereotypes more than problematize them.",13

I want to advance the project of problematizing gender stereotypes by disentangling types of argument or argumentation (linear, abstract, contextual, and narrative) from the gender associations that have regularly featured in gender differences assertions. For a start, it is often not clear what modes or qualities such as "linear," "abstract," "contextual," or "narrative" mean when applied to people's preferences in types of argument. To my mind, these terms initially direct attention to different kinds of cognitive situations or tasks which call for different types of reasoning and argumentation. By "linear" argument we might mean something like deductive reasoning, which is quite appropriate in mathematical and logical contexts when, for example, we seek to show that a conclusion follows necessarily from specific premises. (As regards one aspect of gender, I should note that, having taught hundreds of students de-

12 See Rooney (2001) for my further elaboration of these points. Also see Lorraine Code (1991), esp. pp. 251-262, for an examination of the problematic use of the idea of "women's ways of knowing" in feminist theorizing. In particular, Code is critical of sociological studies and claims about "women's ways of knowing" where the authors do not ask whether such ways of knowing "are the products of women's oppressed social positions, nor do they consider whether a celebration if these 'ways' would be empowering and politically liberating" (1991, p. 260).

13 Bruner, 1996, p. 185. Also see Bonnie Dow and Celeste Condit (2005) for a recent analysis of studies (in Communication) on gender, feminism, and communication. These authors argue that the studies indicate that gender functions in a much more complicated way than that conveyed by earlier male-female differences claims. Catherine Helen Palczewski (1996) provides a helpful overview and critical analysis of feminist work that tends to uncritically reify "feminine" and "masculine" styles of arguing. Michael Gilbert (1994) also critically examines claims of gender differences in argumentation. 
ductive proofs in logic classes, I have yet to see any noticeable gender differences in my students' ability to grasp and do these proofs. Having a female teacher may, however, go some way toward countering the general cultural association of logic with masculinity. ${ }^{14}$ ) Just as linear reasoning may be quite appropriate in deductive reasoning contexts, narrative and contextual expansion may be required in eliciting and then reasoning about the situational and relational complexities of moral situations. For example, most medical ethical arguments and decisions are made using such elaboration. I suspect that, insofar as gender figures into types of reasoning and argument, it figures in secondarily in the way in which cognitive and reasoning tasks were traditionally distributed by gender roles. But such gender distribution does not make the corresponding forms of reasoning or arguing naturally "feminine" or "masculine" in any meaningful sense. However, we cannot overlook the fact that "male" cognitive roles and tasks were typically selected as the models or prime examples of reasoning when philosophers theorized about reason and rationality. ${ }^{15}$

Problems with gender stereotyping also arise in the way that "abstract" reasoning has been contrasted with "contextual" reasoning and argument. Gender differences in moral voice were regularly explained in terms of the greater (male) or lesser (female) use of abstract principles in moral deliberations. However, as I argue in more detail elsewhere (Rooney, 2001), where gender differences seemed to appear, they could have been articulated, just as plausibly, in terms of the application of different types of abstract principles - as applied to different aspects of the moral situations in question. More specifically, abstraction is something of a relative and situated notion, as when we abstract from some of the contextual specifics or saliencies of a given situation and not others. Abstracting from a (multi-faceted) moral situation with respect to particular kinds of relationships and responsibilities among individuals in the situation (as reported of female respondents), and not with respect to specific juridical rights of those individuals as autonomous agents (as reported of male respondents), is one way of abstracting from the situation; another way involves abstracting with respect to the latter and not the former. And these, clearly, need not be the only ways of abstracting. In a sense, then, abstraction and attention to contextual details go hand-in-hand, since abstracting well or appropriately from a given situation typically involves a careful assessment of the contextual particulars and nuances of the situation It is, unfortunately, the traditional association of male-

14 See Pam Oliver (2002) for a critical examination of the cultural associations of rationality and logic with masculinity. Additional critical analyses of feminist issues in formal logic and logical issue in feminist theory appear in Rachel Falmagne and Marjorie Hass (2002).

15 See Rooney, 1995, esp. pp. 29-30 for my fuller elucidation of this claim. 


\section{Phyllis Rooney}

ness with rationality - the latter typically fleshed in terms of principles, autonomy, universality, and abstraction - that seems to automatically lend voice to particular ways of reading gender differences in these contexts and not alternative ways that, I maintain, are just as plausible. In sum, even if gender differences appear (and these have been a matter of some contention), it is important that we resist reading or interpreting them in accord with traditional stereotypes that, instead, require feminist rethinking.

Let us now turn our attention to narrative argument which, perhaps because of its traditional gender association and its association with imagination, has been given woefully little attention in philosophy and informal logic. It is difficult to get a precise definition of "narrative argument," yet it is clear that narrative plays an important role in argumentation, including in philosophy. A good narrative can clearly convey a narrator's position about some issue, and it can also persuade the narrator's audience of that same position. As such, it can constitute an argument, certainly according to a rhetorical view of argument which pays particular attention to audience persuasion. Important evidence relating to personal or cultural experience may be conveyed best in narrative form. In philosophy, counterexamples to philosophical definitions (or arguments) are often presented as narratives about possible situations where the definiens (or premises) are true and the definiendum (or conclusion) is false. Plato's allegory of the cave has featured significantly in philosophical understandings of knowledge. It has functioned as a compelling narrative about the epistemic struggle from vague and shadowy ideas to truth and knowledge. Indeed, the profusion of light and vision metaphors used to convey ideas about knowledge and understanding underscores the significance of the movement from darkness to light narrative in everyday as well as philosophical conceptions of truth and knowledge. (I see what you mean; her explanation threw light on the subject; I'm clearer now about his position; I found her account enlightening.)

Since a significant part of my argument examines the argument-as-war metaphor as a narrative entangled with other philosophical narratives, it is important to reflect on the use of metaphor and narrative as a significant, though often overlooked, component in philosophical argumentation. ${ }^{16}$ In The Philosophy Imaginary, Michèle Le Dœuff not only establishes the crucial role of metaphor and narrative in philosophy, but she also raises important questions about why philosophers have typically overlooked that role. She writes:

\footnotetext{
${ }^{16}$ I this context I am connecting metaphor and narrative insofar as metaphor often works as part of a familiar narrative. For example, winning an argument is a metaphor that makes sense within the argument-as-war narrative of opponents adopting conflicting positions and then attacking or defending these positions until one or the other opponent/position wins out.
} 
Philosophical discourse is inscribed and declares its status as philosophy through a break with myth, fable, the poetic, the domain of the image...The images that appear in theoretical texts are normally viewed as extrinsic to the theoretical work...[but] it is no longer feasible to go on ignoring the importance of imagery in philosophy... [we must reflect on] strands of the imaginary operating in places where, in principle, they are supposed not to belong and yet where, without them, nothing would have been accomplished.... Images are the means by which every philosophy can engage in straightforward dogmatization, and decree a 'that's the way it is' without fear of counter-argument, since it is understood that a good reader will by-pass such 'illustrations' - a convention which enables the image to do its work all the more effectively. (Le Dœuff, 1989, pp. 1, 2, 12)

Le Dœuff proceeds to examine what she takes to be significant metaphors and narratives in some of the canonical works of philosophy. ${ }^{17}$ There is a curious paradox in philosophy, she notes, when philosophers establish the significance of knowledge, truth, understanding, and philosophy itself, using metaphors, images, or fables that in other contexts these same philosophers are likely to characterize as "just" stylistic embellishment, as something which other than, or a distraction from, pure philosophical thinking and content.

To my mind, the best example of this conflict comes from Locke, when he characterizes the proper place of philosophy (with respect to language) as a literal place of order and clarity removed from the tempting "figurative applications" of words:

If we would speak of things as they are, we must allow that all the art of rhetoric, besides order and clearness, all the artificial and figurative application of words eloquence hath invented, are for nothing else but to insinuate wrong ideas, move the passions, and thereby mislead the judgment...where truth and knowledge are concerned [these artificial and figurative application of words] cannot but be thought a great fault, either of the language or person that makes use of them.

\footnotetext{
${ }^{17}$ For example, Le Dœuff notes how, in his Critique of Pure Reason, Kant depicts the "territory of pure understanding...the land of truth" as an island "surrounded by a wide and stormy ocean, the native home of illusion, where many a fog bank and many a swiftly melting iceberg gives the deceptive appearance of farther shores" (Kant, quoted in Le Dœuff, 1989, p. 8).
} 


\section{Phyllis Rooney}

Yet Locke remarks that men are much tempted by such entertainments and deceptions of language, and he then ends this paragraph two sentences later with the following statement: "Eloquence, like the fair sex, has too prevailing beauties in it to suffer itself ever to be spoken against; and it is vain to find fault with those arts of deceiving, wherein men find pleasure to be deceived."18 There are four things to note about this gender metaphor in relation to philosophy, narrative, argument, and gender. First, the metaphor deflects attention from the need for an argument for an assumed premise, that is, that there is a clear distinction (for the philosopher at least) between literal and metaphorical use of language. Second, Locke metaphorically marks the metaphorical and figurative aspects of languages as "feminine" over and against the place of philosophy proper which is thereby symbolized as "masculine." This move reflects the common philosophical depiction of metaphor as stylistic embellishment or decoration of language, as extraneous to the real content of philosophy. Third, the metaphor's appearance in the very same paragraph in which Locke is warning us of the deceptions of metaphor makes one wonder if his gender metaphor is visible as such to Locke. Perhaps it functions as a kind of "invisible" ground metaphor or narrative in philosophy. (I argue that it does in Rooney, 2002.) Fourth, the metaphor seeks to convince the philosophical reader of the tempting but deceiving aspects of figurative language. Yet it establishes the reader as, like Locke, a man among men in a specific cultural milieu with specific attitudes and views about the "fair sex." As metaphor theorists note, metaphors "work" only if they draw on associations or views that are taken for granted by writer and readers.

My examination here of the role of metaphor and narrative in philosophy is clearly designed to counter the recurring portrayal of narrative argument as a more "feminine" type of argument, especially when it is contrasted with the "masculine" linear, logical, abstract forms of reasoning and argumentation that dominate philosophy's self-image. The history of philosophy itself troubles that contrast. But troubling that contrast requires making quite visible the role of sex and gender metaphors, in particular, as something other than "mere" stylistic embellishment in philosophy. As we see with the Locke example, gender associations or assumptions can inform key premises or moves in philosophical argumentation; they often do things that - as Le Dœuff notes about philosophical metaphors more generally-would not get done without them. In section 4 , we will take up this point again when we explore the meta-

\footnotetext{
${ }^{18}$ Locke's metaphor appears in bk. 3, chap. 10, par. 34 of his Essay Concerning Human Understanding. See Rooney (2002) for further discussion of this metaphor. There I also examine other examples of the metaphorical construction of the linguistic place of pure or proper philosophy as a "masculine" place.
} 
phorical construction of reason as battling philosophy's imaginary construction of "woman." Le Dœuff sums up philosophy's "portrait of "woman"" as, "a power of disorder, a being of night, a twilight beauty, a dark continent, a sphinx of dissolution, an abyss as of the unintelligible, a voice of underworld gods... a place where all forms dissolve" (Le Dœuff, 1989, p. 113).

But first, let us reflect further on the role of the argument-aswar metaphor in philosophical understandings and conceptions of a key practice of reason, argument and argumentation.

\section{Minimal adversariality?}

Disagreement plays an important role in inquiry, in the furtherance of truth, understanding, and knowledge. Given the fact that argumentation is a practice that is typically bound up with the working out of disagreement, how much adversariality is required for the epistemically productive use of argumentation? While our main focus in this section is argumentation as an epistemic practice involving rational persuasion and truth-seeking, there are other forms of argumentation that don't readily fall within this epistemic purview. Arguments are often about which action to take or which policy to adopt, and these arguments may involve some level of adversariality, especially when arguers' personal interests, preferences, and values are at stake. (Indeed, some form of adversariality may be required when there is a threat to someone's sense of integrity, value, or self-respect. Perhaps a form of "just war" may apply in such situations.) Yet these arguments often have an epistemic component, involving claims to the effect that action or policy $\mathrm{A}$ is likely to be more effective than action or policy B (where there is some prior agreement about what constitutes effectiveness in the given situation). Evidence of past success with A or B (or with aspects of A or B) can be brought to bear in determining the likely truth of such claims. Thus, we can take the determination of truth or likely truth to be a significant component of most arguments in a dialectical context - which can also include arguments with oneself. Govier captures important epistemic factors in her understanding of good arguments as tools of inquiry which involve claims that are "in some way at issue," where evidence is submitted to justify claims, where there is an honesty and openness about the existence of disagreement or doubt, and where possibilities of rational persuasion exist (Govier, 1999, pp. 45-51). She adds, "I would submit that argument is not necessarily confrontational [in the ancillary sense] and that adversariality can be kept to a logical, and polite, minimum...[A]rgument may embrace the positive goals of persuasion and justification without necessitating adversariality in any negative sense" (p. 55). 
There are many reasons to impugn what Govier calls "ancillary adversariality" in argumentation, in addition to the fact that it can discourage people less comfortable with combative styles of interaction. Standard philosophical norms of good reasoning and arguing also impugn aspects of ancillary adversariality that hinder the careful expression and assessment of arguments. Fallacies such as ad hominem and straw man expressly prohibit the kinds of personal attack and distortion of opponents' positions that a hostile and combative environment is likely to foster. On the more constructive side, many norms or principles of argumentation endorsed by informal logicians and argumentation theorists specifically encourage practices of respectful listening and careful assessment of evidence from different perspectives. Among such recommended dialectical rules of procedure are the Principle of Charity, Paul Grice's "cooperative principle," and the specific rules of the pragma-dialectical school of argumentation. ${ }^{19}$

I agree with Govier that feminist concerns with ancillary adversariality do not impugn argument per se, and that, in any case, there are "good independent reasons" for discouraging the antagonistic, coercive, or militaristic aspects of argumentation that have concerned many feminists. ${ }^{20}$ But not all feminist critiques are directed toward this level of adversariality and the ways it can (given gender socialization) disproportionately discourage and silence women. As I will argue, a specifically-feminist critique can be directed, not just to the practice of argumentation, but to the ways in which such practice is supported by philosophical and logical conceptions of argument and argumentation that uncritically incorporate competition and battle imagery. I will next argue that Govier's minimal adversariality, which she maintains is appropriate, perhaps even necessary in argumentation, also involves elements of battle that are not warranted.

\footnotetext{
${ }^{19}$ For a helpful account of these developments in argumentation theory, see van Eemeren et al. (1996). Michael Scriven takes the Principle of Charity to require " that we try to make the best, rather than the worst, possible interpretation of the argument we're studying." He argues that it also proscribes "taking cheap shots," "nit picking," and "setting up a straw man" (van Eemeren et al., p. 170).

${ }^{20}$ In these contexts Govier is primarily addressing feminist critiques that impugn argument (generally) as aggressive or coercive practice. For example, in her paper supporting "the womanization of rhetoric," Sally Gearhart maintains that "any intent to persuade is an act of violence" (Gearhart, 1979, p. 195). Also see Maryann Ayim (1988) for a discussion of "violence and domination as metaphors of academic discourse"-metaphors that, she notes, are often linked with imagery of sexual domination. Some have interpreted Andrea Nye's (1990) feminist examination of the history of logic (with logic's use of "words of power") along similar lines. Richard Fulkerson, among others, has argued that some of these critiques rely too heavily on "essentializing stereotypes" of competitive men and cooperative and nurturing women---the kinds of stereotypes we examined in section 2 above. See Fulkerson, 1996, esp. pp. 206-210.
} 
It would certainly seem that minimal adversariality is inevitable, Govier argues, given the fact that people have definite (and different) beliefs or opinions. When a situation arises where differences need to be addressed, disagreements, criticisms, challenges of others' premises naturally result. Govier describes such a situation in a series of steps, using what we can recognize as a paradigm case of such difference-where I hold X and you hold not-X. She notes where minimal adversariality can readily make an appearance in our description of our working through the disagreement, but it need not be considered especially negative or destructive (Govier, 1999 , p. 244). From our basic difference, and my holding X (step 1 ), we are likely to say that I think that $X$ is correct (step 2), and that I think that not-X is not correct (step 3), Govier notes. From there one could quite naturally say that I think that anyone who holds not-X (including you) is wrong, or is making a mistake (step 4). Govier does not question this move in our admittedly common or natural description of our disagreement, but I suggest that there is already more confrontation elicited here than is necessary. To go from saying that I think that your belief not- $\mathrm{X}$ is mistaken or incorrect to "you are wrong" is surely an extra and unnecessary step. It illustrates a problematic slippage that is not uncommon in argumentation, the slippage from a person's belief or claim (as wrong) to the person herself (as wrong). It introduces a level of adversariality that is unnecessary and epistemically confusing, and, to my mind, borders on the very thing Govier wants to avoid, "the ancillary aspects of adversariality commonly attendant upon [minimal adversariality] and thus naturally and readily confused with it" (p. 245).

Govier does render "questionable" the next 2 assertions which, again, we might very easily and naturally make in describing this argument situation. "Should I need to argue for X, I will thereby be arguing against not-X" (step 5); "Those who hold not-X are, with regard to the correctness of $\mathrm{X}$ and my argument for $\mathrm{X}$, my opponents" (step 6) (p. 244, my emphases). While I agree with Govier that we often quite commonly say such things, I want to render them even more questionable. With regard to step 5, I could just as easily, and perhaps more accurately, say that I am arguing with not$\mathrm{X}$ and with your argument for not-X, in that I am taking into consideration and reasoning with your evidence and your reasoning for not-X, even if at the end of the exchange I still hold X? Isn't this argument a particular kind of conversation (one where we are working through differences in beliefs), and don't we normally say we converse with rather than against people or their conversation? Relating to step 6, why are you my "opponent" if you are providing me with further or alternative considerations in regard to $X$, and, again, whether I end up agreeing with $\mathrm{X}$ or not-X? Given the use of "opponent" in step 6, we are now very close to an additional step 
(though not given by Govier) which involves a claim we also readily make in the event that, after our exchange of evidence and reasoning, I end up agreeing with your not-X. I lose the argument and you win (step 7). But surely I am the one who has made the epistemic gain, however small. I have replaced a probably false belief with a probably true one, and you have made no such gain (though, of course, you might claim some achievement and satisfaction in helping me to my epistemic gain).

What I am suggesting with my questioning of this combative wording is not that we should resist it in order to be more polite, but that this wording is misdescribing the argument situation, quite significantly from an epistemic point of view. It is easy to think in terms of "opponents" when there is "conflict of beliefs," Govier notes. Yet even talking about conflicting or opposing beliefs is already something of a misnomer when we have perfectly fine epistemic or logical terms such as "contradictory" or "inconsistent" which more precisely describe what the "conflict" is. The fact that such minimal antagonism is comfortably embedded in what we take to be quite natural, common descriptions (misdescriptions) of this and similar argument situations suggests that the boundary between Govier's minimal and ancillary adversariality is more porous than we might initially think. (In rendering steps 5 and 6 questionable Govier perhaps thinks so too.) Battle images and wording cut across both. War-like metaphors (shooting down points, attacking positions and persons, going after fatal flaws, and so on), often enacted more explicitly and problematically with ancillary adversariality, have their less bellicose cousins - but cousins still — in the minimal adversariality informing basic understandings and descriptions of argument and argumentation. They do so to the extent that, as I maintain above, we barely recognize them as such, even when they are characterizing argument situations in epistemically erroneous and confusing ways.

Others have also drawn critical attention to the argument-aswar metaphor and its problematic role in the understanding and practice of argument as a tool of rational persuasion. In connection with what he calls "the ideology of argumentation" Daniel Cohen notes, "What the pervasive argument-is-war metaphor reveals is that the operative ideology [of argumentation] commits us, if not to truth and falsity, or to right and wrong sides, at the very least to winners and losers." ${ }^{21}$ Stressing the positive epistemic role of rational persuasion in argumentation, Ralph Johnson implicitly criticizes the way in which a win-lose calculus can obscure the goals of truth and good reasoning: "one reason argumentation is such a powerful practice is that if each party does its very best, then both sides will gain as a result of the process" (Johnson, 2000, p. 243).

${ }^{21}$ Cohen, 1995, p. 181. Cohen also discusses this metaphor in Cohen, 2004. 
Under the shadow of its dominant metaphor, argumentative reasoning can become "pedantic and petty," Cohen adds. It can presuppose that "the subject at hand can be carved into distinct and opposing positions, and this tends to squeeze the discussion of even the most complex questions into a black-and-white view of the world." Insight and understanding are likely to be trumped by "cleverness and rhetorical dexterity" (Cohen, 1995, pp. 180-181). Cohen does not exclude arguments in philosophy in this assessment. Though he does not mention Moulton's work, some of his concerns clearly echo problems she had with the way in which the paradigmatic Adversary Method can significantly constrict philosophical reasoning and argumentation.

In this section it looks like I have done what I earlier noted that Moulton and Govier had done. I have examined problems with adversarial argumentation, and minimal adversariality in particular, as not-specifically-feminist problems. My position largely rests on generally accepted epistemic and epistemological concepts and claims about differences and disagreements in beliefs, about adducing evidence in support of beliefs or their negations, and about arriving at beliefs that are more likely to be true. But this is not the end of the story, of course. It is the beginning of a new one. Some central questions now loom: Given some of the obvious problems with adversariality, now acknowledged in many circles (not just feminist ones), how did adversariality (with its attendant argumentas-war metaphor) become so implanted in understandings and conceptions of argument in the first place, and especially in philosophy? Why has it taken so long to see its problems? A better understanding of how we got ourselves into this problematic and paradoxical situation might also give us an understanding of how we might get ourselves back out of it. I will now proceed to examine adversariality in a way that renews feminist attention on it, yet does not assume controversial claims about (natural or socialized) gender differences in styles or modes of reasoning and arguing. Feminist epistemological analyses are sometimes described as, simply, "making gender visible," and I now proceed to make gender visible in metaphorical constructions of embattled reason and its natural offspring argument-as-war. ${ }^{22}$

\section{Embattled reason}

A year after the publication of Moulton's paper, Genevieve Lloyd's Man of Reason appeared, and this work proved to be a significant

\footnotetext{
${ }^{22}$ Helen Longino has proposed as "a bottom line requirement of feminist knowers [of knowledge and of epistemology]...that they reveal or prevent the disappearing of gender' (1994, p. 481).
} 
impetus for feminist work on the history of Western philosophy and feminist work on reason (Lloyd, 1993 [1984]). Lloyd pays particular attention to the historical perseverance of the "maleness" of reason in the Western philosophical tradition. She documents the ways in which philosophical understandings of the value and power of reason regularly involved some form of denigration, control over, distance from, or transcendence of "woman" or "the feminine." She traces "the implicit maleness of our ideals of Reason" through different philosophical eras, through different approaches to conceptualizing reason, and, indeed, through different historical understandings of male-female differences. The stage was well set in Greek theories of knowledge, she notes. "From the beginnings of philosophical thought, femaleness was symbolically associated with what Reason supposedly left behind--the dark powers of the earth goddesses, immersion in unknown forces associated with mysterious female powers." 23

Aristotle not only thought that women were (in a literal sense) less capable of reason than men, but woman also symbolically represented the irrational element of the soul: "in the soul too there is something contrary to the rational principle, resisting and opposing it...[the relationship between these parts of the soul] metaphorically resembles that between master and servant or that between husband and wife." 24 Philo, the first-century Alexandrian, echoed Aristotle's theme: "[there are] two ingredients which constitute our life-principle, the rational and the irrational; the rational which belongs to mind and reason is of the masculine gender, the irrational, the province of sense, is of the feminine. Mind belongs to a genus wholly superior to sense as man is to woman" (Philo, quoted in Lloyd, 1993, p. 27). Augustine associated a lesser practical form of reason with "woman's corporeal veil," which was distinguished from the part of the mind and Reason directed to "the contemplation and consideration of the eternal reasons" (Augustine, quoted in Lloyd, 1993, p. 31). Aquinas's association of women with sin reflects the Medieval entanglement of philosophy with theology: the construction of woman as temptress, as identified with body and sexuality, determined her diminished status in both philosophy and theology.

In later centuries, when philosophers sought to develop conceptions of reason, knowledge, and consciousness in terms of a more harmonious relationship with Nature (Rousseau), or in terms of a reconciliation of human reason with the rationality of Nature

\footnotetext{
${ }^{23}$ Lloyd, 1993 [1984], p. 2. The association of femaleness with darkness and of maleness with light can be examined in connection with the significance of the movement from darkness to light metaphor/narrative in philosophical understandings of knowledge.

${ }^{24}$ Aristotle, Nicomachean Ethics, quoted in Rooney, 1991, p. 81. (My emphases).
} 
(Kant), or in terms of endorsing a conception of Reason as the unfolding of Nature (Hegel), the symbolic or actual woman still does not fare well by ideals of reason. Woman now regularly represents an instinctual or immature stage of nature and consciousness, a stage that must be transcended in the full self-conscious realization of Nature and Reason. In what may seem like a reversal, Nietzsche asks us to "suppose truth is a woman." His association, however, serves not so much to elevate women, but to disparage truth, especially the traditional slavish following of truth as a dogmatic illusion that impedes true exuberance and creativity. The American pragmatist, C. S. Peirce, underscores the importance of clear ideas and thought by warning "us" about what happens to a young man who clings too long to "some vague shadow of an idea." Such a man wakes up "some bright morning to find it gone, clean vanished away like the beautiful Melusina of the fable, and the essence of his life gone with it." 25

Gender metaphors thus establish a recurring philosophical narrative: following the path of reason, clarity, and knowledge requires a constant vigilance against the ever-lurking threats of distractions of "feminine" unreason: emotion, body, sexuality, instinct, nature, or wily charms. ${ }^{26}$ What is especially significant for our feminist purposes here is not that gender imagery is used, but how it is used. Gender doesn't function as a "different but equal" type of categorization. Reason is significantly valued through a simultaneous devaluing of a "feminine" aspect or principle that the man of reason must continually monitor, control, reject, or transcend. ${ }^{27}$ A misogyny-inflected cultural imaginary is the taken-forgranted or assumed background that fills the gap between the gendering of a particular aspect of mind or experience (passion, body, nature, chaos, or indeterminacy) as "feminine," and the automatic determination of that same aspect as something to be denigrated, rejected, or transcended. Without such an assumed background functioning essentially as a missing premise, that move couldn't be made, the metaphor wouldn't "work." Metaphor theorists argue that in order for metaphors to work, they must draw upon a "system of associated commonplaces" shared by the writer and intended readers. As one prominent theorist noted, "the important thing for

\footnotetext{
${ }^{25}$ Peirce, quoted in Rooney, 1991, p. 85. See this paper for more examples and further analysis of the metaphorical gendering of reason.

${ }^{26}$ It is important to note that the "slave" (as in the Aristotle quote) or the "primitive" also regularly took the place of that which is "other" to reason and true knowledge. That is, gender was not the only social category used to mark that which is excluded from the realm of reason. See Mills (1997) for a discussion of the role of racism in epistemological and political theorizing.

${ }^{27}$ As Lloyd notes in a later paper on metaphors of maleness and reason, the male/female distinction in philosophical texts is "a vehicle of evaluation. It serves to privilege, through oppositional contrasts, some aspects of mind over others" (Lloyd, 2002, p. 86).
} 
the metaphor's effectiveness is not that the commonplaces shall be true, but that they should be readily and freely evoked" (Black, 1962 , p. 40). The shared background of many of these freely evoked images is a cultural imaginary drawn in part from mythological associations carried by the Furies and Sirens in classical times, and by Witches in more modern times - a mythological heritage making its appearance in a discourse that, as Le Dœuff notes, regularly declares its status as philosophy through a break with myth and fable.

As many of the examples above also show, the valuing and devaluing inscribed by gender metaphors is played out as a continual battle, with reason battling over or against ever-threatening "feminine" aspects. Gender is battle here, and "male" reason is embattled reason. Metaphors of battle are quite explicit in other contexts. In the Republic, for example, Plato discusses the type of philosophical reasoning needed to abstract and analyze the Form of the Good, a reasoning that is able to distinguish appearance from reality and knowledge from opinion. The man who is to "really know the good itself...[must] as it were in battle [run] the gauntlet of all tests... and hold on his way through all this without tripping in his reasoning." 28 In his important epistemological work, The Posterior Analytics, Aristotle symbolically compares the step-bystep rational integration of undifferentiated empirical perceptions and experiences with standing against a rout in battle: "It is like a rout in battle stopped by first one man making a stand and then another, until the original formation has been restored." 29 The "original formation" indicative of the growth of knowledge and understanding thus emerges as something like a well-disciplined army. Militaristic metaphors pepper Descartes's Passions of the Soul. The properly disciplined will, as an ally of mind and reason, must struggle against primitive instincts and passions as "animal spirits," using the soul's "proper arms" of determinate judgments of good and evil (Lloyd, 2002, p. 86). Some centuries (and many similar metaphors) later, Wittgenstein describes the philosopher's proper vigilance with language in a way that entangles gender with battle quite explicitly, "Philosophy is a battle against the bewitchment of our intelligence by means of language." ${ }^{30}$ A lapse in such vigilance

\footnotetext{
28 Plato, Republic, Bk VII, 534bc. This translation is by Paul Shorey (Loeb Classical Library, Harvard University Press, 1935).

29 Aristotle, Posterior Analytics, Bk. II, ch. 19. This translation is by Richard McKeon (The Basic Works of Aristotle, New York: Random House, 1941).

30 Wittgenstein, Philosophical Investigations, § 109 (trans. by G. E. M. Anscombe, New York: MacMillan, 1953). The German word Wittgenstein uses, "die Verhexung," is appropriately translated as "bewitchment." The gender association is marked by the root word "Hexe," meaning witch. For a further analysis of the function of this and similar metaphors in Wittgenstein's demarcation of the proper role of philosophy vis à vis language, see Rooney, 2002.
} 
echoes Peirce's lapse in clarity of language and thought, which he (Peirce) represents in terms of the captivation and abandonment by the beautiful (and presumably bewitching) Melusina of the fable.

We need to be clear about how gender is working in these recurring gender/battle images. There are two gender battles at issue. The more immediate textual one is not a battle between men (or masculinity) and women (or femininity), but the battle within men between their "masculine" rational aspects or parts and their "feminine" irrational aspects or parts. It is the defensive struggle within men against what they perceive or construct as inferior "feminine" tendencies within themselves. ${ }^{31}$ To the extent that women might also aspire to the "man of reason" ideal, they too, presumably, would battle their "feminine" aspects, though, even in sexism-infused cultural contexts, these metaphors might not work in quite the same way for them. However, this battle between parts of mind, soul, or experience derives from an original battle between men (or masculinity) and women (or femininity), as that battle is constructed by men in specific historical-cultural contexts. It is a battle that primarily makes sense to men among men in cultural contexts where sexism or misogyny is a cultural given that infuses imagination and language, among other things.

Philosophical understandings of argument and argumentation (as a, if not the paradigmatic practice of reason or reasoning) have not escaped the dictates of the metaphorical construction of embattled reason. Success in arguing (reasoning) is fundamentally bound up, metaphorically, with success in maleness overcoming or controlling a threatening non-rational femaleness. In a dialectical context, argumentation symbolically pits two or more opponents (two "men of reason") who are both battling for the rational, masculine position. The battle over one's opponent is now amplified as a battle to avoid the "feminine" position, as the losing position is now symbolically constructed. Perceived failures in argumentation are often feminized, sometimes articulated as "wimping out" or "chickening out." Success in arguing is, therefore, success in battling; in effect, argument is war.

In her paper addressing gender metaphors more explicitly, Lloyd notes how symbolic operations interact with the social formation of gender identity: "Masculine socialization influences which symbols male authors choose and how they operate with them. And those uses of symbols influence in turn the social formation of gender identity" (2002, p. 75). Because of this long historical interaction, and because masculine gender socialization and identity is still significantly informed by sexism, uncovering and uprooting the effects of sexism-informed gender symbolism in philosophical texts and imaginations is no easy matter. Recent

${ }^{31}$ My thanks to Robert Pinto for stressing this point of clarification. 
work in masculinity theory helps to shed light on the lingering connections between the (however distant) philosophical constructions of embattled/masculine reason and contemporary sociocultural constructions of masculinity. In this work (which provides a necessary complement to feminist examinations of socio-cultural constructions of femininity) there is recurring mention of early male development, and, in particular, of the significant role that sexism plays in the construction of masculine identity. In reflecting on his teenage years, Patrick Hopkins notes that the most popular insult/name used by boys with other boys was, simply, "girl." The "blatantly sexist use of the word 'girl'...like other terms ['faggot', 'homo'] signifies a failure of masculinity, a failure of living up to a gendered standard of behavior, and a gendered standard of identity" (Hopkins, 1996, pp. 95-96). Michael Kimmel, among others, has amplified this point. He argues that "manhood is socially constructed...historically and developmentally, masculinity has been defined as the flight from women, the repudiation of femininity...Being a man means 'not being like women'...Masculinity is the relentless repudiation of the feminine" (Kimmel, 1994, pp. 125126). The recurring taunts of "gay," "sissy," "wimp," Kimmel argues, construct masculinity as something that must be continually, relentless proved, producing constant fear of emasculation.

Kimmel maintains that "homosocial enactment" and "homosocial competition" of men among men play a significant role in male identity and experience, at least in the cultural contexts he examines. ${ }^{32}$ Some studies indicate that such competition also informs men's styles of communication and argumentation, whether in male-male or male-female interactions. Among studies of gender differences in communication are some that point to a man's need to continually navigate his way through "a hierarchical social order in which he [is] either one-up or one-down...oral disputation is inherently adversative...oral performance is self-display...is part of a larger framework in which many men approach life as a contest., ${ }^{, 33}$

${ }^{32}$ Kimmel is careful to note that his main focus is "American manhood," and that the definition of manhood he is examining is that of white, middle-class, heterosexual men. Yet that definition, he adds, "continues to remain the standard against which other forms of manhood are measured and evaluated" (Kimmel, 1996, p. 124).

${ }^{33}$ Deborah Tannen (1990, 24, p. 150). Not unlike Gilligan in her discussions of gender differences in moral reasoning, Tannen sometimes discusses these differences in the mode of, "women are more like this, men are more like that, and vive la différence." This gets us back to the recurring and tricky balancing act of, on the one hand, recognizing and understanding gender differences (which are always context-relative and often contested, in any case), and, on the other hand, not reinforcing and normalizing the status and power disparities and injustices that give rise to such differences. We should also keep in mind that, as with women and norms of femininity, there are varying degrees of resistance and con- 
With reference to such studies, Michael Gilbert expands, "For many men, arguing without being committed or as devil's advocate is the intellectual equivalent of schoolyard roughhousing... arguing can be very aggressive and apparently antagonistic, but also exhilarating and downright enjoyable to those to whom it is considered play" (Gilbert, 1995, p. 102). Gilbert's expansion helps to explain why philosophical discussions sometimes play out as competitive sports contests, and why those of us who don't quite get it are likely to be told that we shouldn't take it too personally, since, after all, it's just fun or play in exercising one's philosophical chops.

When I read these accounts of male development and experience, I must say that I better understand why I have sometimes felt like a stranger in a strange land as I've observed male philosophers arguing among themselves. These interactions often converge on an interminable battle about what I had understood to be a fairly minor (perhaps irrelevant) point in the overall argument or discussion. Insight or understanding about the larger significant philosophical issue at hand is often left behind in the rush to score the point or win the argument. Normative masculinity based on relentless homosocial competition seems to inform the fear of failure (linked, according to Kimmel, to a fear of emasculation) that losing an argument would seem to entail-even a nitpicking, pedantic, or trivial one! Yet this is perhaps no longer strange or surprising. For we have here homosocial competition operating in a discipline that is still, (outside relatively marginalized feminist philosophy circles) largely resistant to critically uncovering and uprooting the full effects of its gender history, a history that inspired and still informs this particular cultural construction of masculinity. Yet - and here I'm surmising as something of outsider again - there seems to be some code of silence among male philosophers about openly challenging these particular (and to many women, peculiar) constructions of masculinity. For them to do so would, it seems, automatically place them in a one-down position in the specific culture of homosocial enactment that the discipline often still exhibits.

\section{Conclusion}

I have made a case for various entanglements and disentanglements in this paper, but one of each predominates. I have argued for disentangling, from discussions of gender-inflected adversariality in philosophy especially, particular kinds of gender assumptions and claims. In particular, I have challenged the default assumption that women are less comfortable with adversarial argumentation be-

formity that individual men adopt in relation to local norms or expectations of masculinity. 
cause they are generally more cooperative and supportive. Such an assumption typically derives from claims about gender differences that are at best contested, that do not take full account of the ways in which gender operates with other social variables, and differently in different social and cultural contexts. Just as gender lends itself to different interpretations and understandings, so too does adversariality.

I have argued for a specific link between gender and adversariality in philosophy, one that pays particular attention to philosophy's history and culture. That examination involves entangling (or, perhaps, re-entangling) the adversariality question with the discipline's history of sexism and misogyny, and especially with feminist philosophical reflections on that history. I've argued that in this context the key gender differences we need to attend to are those that are metaphorically and symbolically constructed in the philosophical canon. The question of gender differences in comfort levels with adversarial argumentation now emerges somewhat differently. It has to do with the fact that women philosophers are less attached to historical associations and metaphors that have incorporated aspects of a sexist history and culture that the discipline as a whole still tolerates - at least to the extent that it continues to marginalize feminist work uncovering that history and culture. As Lloyd stresses,

The linking of the symbolism of the male-female distinction with the understanding of rationality is a contingent feature of Western thought, the elusive but real effects of which are still with us... There can be real discomfort for women in attempting to speak form those supposedly neutral positions that have been constituted by and for male thinking subjects for whom the [male-female] oppositions came naturally" (2002, p. 81).

Although most philosophers (both female and male) now distance themselves from the more explicit sexist and misogynistic passages in the history of Western philosophy, we all absorb, to some extent, that history's gender associations when we uncritically absorb aspects of the history and culture of philosophy that I have explored in this paper. Too many philosophers still suppose that gender metaphors in philosophy functioned as "mere" stylistic embellishment. Or they maintain that sexist comments about actual women were "mere" historical curiosities of more sexist times, that they can be set aside from the real philosophical content of historical texts that still inform the core concepts and questions of the discipline. Yet significant feminist scholarship during these past decades has gone quite some distance toward undermining such ready suppositions and assertions. 
There are significant advantages in furthering critical examinations of philosophy's gender-inflected and limited understandings and practices of adversariality. To the extent that we are all still influenced by forms of adversarial argumentation that significantly constrain philosophical discussion, insight, and understanding we are poorer reasoners and arguers than we might otherwise be. From the point of view of good philosophical development and the many reasonings, arguments, insights, understandings, truths, or wisdom it may yet reveal, philosophy's peculiar adversariality is not just a problem for women. It is a problem for anyone who wants to promote the value of philosophy as a discipline that is genuinely welcoming of the variety of arguments, views, and perspectives that it — in theory at least — claims to welcome.

Acknowledgements: I presented an early version of parts of this paper at the Ontario Society for the Study of Argumentation conference in 2003. I am grateful to audience members there for helpful discussion, and especially to Robert Pinto for his thoughtful written comments on that paper (Rooney, 2003). I also thank Catherine Hundleby for her suggestions and support in the development of this paper. Patricia Trentacoste, Sharon Crasnow, and two anonymous reviewers for this journal also provided very helpful comments on an earlier draft of the paper.

\section{References}

Ayim, Maryann. (1988). Violence and Domination as Metaphors in Academic Discourse. In: Trudy Govier (ed.), Selected Issues in Logic and Communication (pp. 184-195). Belmont, CA: Wadsworth.

Black, Max. (1962). Models and Metaphors. Ithaca, NY: Cornell University Press

Bruner, M. Lane. (1996). Producing Identities: Gender Problematization and Feminist Argumentation. Argumentation and Advocacy 32(4): 185-198.

Burgess-Jackson, Keith. (2002). The Backlash Against Feminist Philosophy. In: Superson and Cudd (2002), pp. 19-47.

Code, Lorraine. (1991). What Can She Know? Feminist Theory and the Construction of Knowledge. Ithaca, NY: Cornell University Press.

Cohen, Daniel H. (1995). Argument is War...and War is Hell: Philosophy, Education, and Metaphors for Argumentation. Informal Logic 17(2): 177-188.

------. (2004). Arguments and Metaphors in Philosophy. Lanham, MD: University Press of America. 
Crasnow, Sharon. (2009). What Do the Numbers Mean? American Philosophical Association Newsletter on Feminism and Philosophy, vol. 8, no. 2 (Spring 2009): 13-16. Available at:

http://www.apaonline.org/publications/newsletters/v08n2 Femini $\underline{\text { sm 09.aspx }}$

Dow, Bonnie J. and Celeste M. Condit. (2005). The State of the Art in Feminist Scholarship in Communication. Journal of Communication 55 (3): 448-478.

Falmagne, Rachel Joffe, and Marjorie Hass (Eds.). (2002). Feminist Theory and Formal Logic. Lanham, MD: Rowman \& Littlefield

Frey, Olivia. (1990). Beyond Literary Darwinism: Women's Voices and Critical Discourse. College English 52(5): 507-26.

Fulkerson, Richard. (1996). Transcending Our Conception of Argument in Light of Feminist Critiques. Argumentation and Advocacy 32(4): 199-217.

Gearhart, Sally Miller. (1979). The Womanization of Rhetoric. Women's Studies International Quarterly 2: 195-201.

Gilbert, Michael A. (1994). Feminism, Argumentation and Coalescence. Informal Logic 16(2): 95-113.

------. (1997). Coalescent Argumentation. Mahwah, NJ: Lawrence Erlbaum Associates.

Gilligan, Carol. (1982). In a Different Voice: Psychological Theory and Women's Development. Cambridge, MA: Harvard University Press.

Govier, Trudy. (1999). The Philosophy of Argument. Newport News, Virginia: Vale Press.

Grimshaw, Jean. (1987). Philosophy and Aggression. Radical Philosophy 47 (Autumn 1987).

Harding, Sandra, and Merrill B. Hintikka. (1983). Discovering Reality: Feminist Perspectives on Epistemology, Metaphysics, Methodology, and Philosophy of Science. Dordrecht, Holland: D. Reidel.

Haslanger, Sally. (2008). Changing the Ideology and Culture of Philosophy: Not By Reason (Alone). Hypatia 23 (2): 210-223.

Hopkins, Patrick D. (1996). Gender Treachery: Homophobia, Masculinity, and Threatened Identities. In: Larry May, Robert Strikwerda, and Patrick D. Hopkins (eds.), Rethinking Masculinity: Philosophical Explorations in Light of Feminism. Second Edition (pp. 95-115). Rowman \& Littlefield Publishers.

Johnson, Ralph H. (2000). Manifest Rationality: A Pragmatic Theory of Argument. Mahwah, NJ: Lawrence Erlbaum Associates.

Kimmel, Michael. (1994). Masculinity as Homophobia: Fear, Shame, and Silence in the Construction of Gender Identity. In: Harry Brod and Michael Kaufman (eds.), Theorizing Masculinities (pp. 119-141). Thousand Oaks, CA: Sage Publications. 
Adversarial Argumentation and Embattled Reason 233

Kourany, Janet. (2009). Why Are Women Only 21\% of Philosophy?: Introduction to the Panel Presentations. American Philosophical Association Newsletter on Feminism and Philosophy 8(2, Spring 2009): 9-10. Available at:

http://www.apaonline.org/publications/newsletters/v08n2_Femini sm 07.aspx.

Lakoff, George, and Mark Johnson. (1980). Metaphors We Live By. Chicago, IL: University of Chicago Press.

Lewis, Brooke. (2009). Where Are All the Women? The Philosophers Magazine 47 (September 2009). Also available at: http://www.philosophypress.co.uk/?p=615.

Le Dœuff, Michèle. (1989). The Philosophical Imaginary. Trans. C. Gordon. Stanford, CA: Stanford University Press.

Lloyd, Genevieve. (1993 [1984]). The Man of Reason: 'Male' and 'Female' in Western Philosophy. Second edition. Minneapolis, MN: University of Minnesota Press.

-----. (2002). Maleness, Metaphor, and the 'Crisis' of Reason. In L. M. Antony and C. E. Witt (Eds.), A Mind of One's Own: Feminist Essays on Reason and Objectivity. Second Edition (pp. 73-89). Boulder, Colorado: Westview Press.

Longino, Helen. (1994). In Search of Feminist Epistemology. The Monist 77(4): 472-485

Menssen, Sandra. (1993). Do Women and Men Use Different Logics?: A Reply to Carol Gilligan and Deborah Orr. Informal Logic 15(2): 123-138.

Mills, Charles. (1997). The Racial Contract. Ithaca, NY: Cornell University Press

Moulton, Janice. (1989). A Paradigm of Philosophy: The Adversary Method. In: Sandra Harding and Merrill B. Hintikka (Eds.), Discovering Reality: Feminist Perspectives on Epistemology, Metaphysics, Methodology, and Philosophy of Science (pp. 149-164). Dordrecht, Holland: D. Reidel.

Nye, Andrea. (1990). Words of Power. New York: Routledge.

Oliver, Pam. (2002). "What Do Girls Know Anyway?": Rationality, Gender, and Social Control. In: Falmagne and Hass (2002), pp. 209-232.

Orr, Deborah. (1989). Just the Facts Ma'am: Informal Logic, Gender and Pedagogy. Informal Logic 11(1): 1-10.

Palczewski, Catherine Helen. (1996) Special Issue: Argumentation and Feminisms. Argumentation and Advocacy 32(4): 161-169.

Penaluna, Regan. (2009). Wanted: Female Philosophers, in the Classroom and in the Canon. The Chronicle of Higher Education, October 11.

Rooney, Phyllis. (1991). Gendered Reason: Sex Metaphor and Conceptions of Reason. Hypatia, 6(2): 77-103.

(1995) Rationality and the Politics of Gender Difference. Metaphilosophy 26(1-2): 22-45. 
(2001). Gender and Moral Reasoning Revisited: Reengaging Feminist Psychology. In: Peggy DesAutels and Joanne Waugh (Eds.), Feminists Doing Ethics (pp. 153-166). Lanham, MD: Rowman and Littlefield.

------. (2002). Philosophy, Language, and Wizardry. In Naomi Scheman and Peg O'Connor (eds.), Feminist Interpretations of Ludwig Wittgenstein (pp. 25-47). University Park, PA: Penn State Press.

------. (2003) Feminism and Argumentation: A Response to Govier. Presented at the 2003 Ontario Society for the Study of Argumentation (OSSA) Conference, Informal Logic at 25. Available at: http://web2.uwindsor.ca/faculty/arts/philosophy/ILat25/edited rooney.doc

-----. Forthcoming. The Marginalization of Feminist Epistemology and What That Reveals about Epistemology 'Proper'. In: Feminist Epistemology and Philosophy of Science: Power in Knowledge, ed. Heidi Grasswick. Dordrecht, Holland: Springer.

Superson, Anita M. and Ann E. Cudd (Eds.). (2002). Theorizing Backlash: Philosophical Reflections on the Resistance to Feminism. Lanham, MD: Rowman \& Littlefield.

Tannen, Deborah. (1990). You Just Don't Understand: Women and Men in Conversation. New York, NY: HarperCollins.

Van Eemeren, Frans H., Rob Grootendorst, and Francisca Snoeck Henkemans. (1996). Fundamentals of Argumentation Theory: A Handbook of Historical Backgrounds and Contemporary Developments. Mahwah, NJ: Lawrence Erlbaum Associates.

Warren, Karen. (1988). Critical Thinking and Feminism. Informal Logic 10(1): 31-44. 